\title{
Managing Time: A Study Among Arab Open University Tutors In Kuwait Branch
}

Abdin M. Sharif, Arab Open University, Kuwait

Omer H. Ismail, Sultan Qaboos University, Sultanate of Oman

\begin{abstract}
The purpose of this paper was to investigate how tutors at the Arab Open University (AOU) in Kuwait Branch manage their time given workloads they are assigned. Group interviews were conducted with a sample that was selected from AOU tutors in Kuwait branch. The findings showed that tutors do not ask for more time or cut down workloads; instead, they ask for a better organized and healthy work environment where they can make use of the available time and be more productive and creative.
\end{abstract}

Keywords: Teaching load; Time management; Arab Open University

\section{INTRODUCTION}

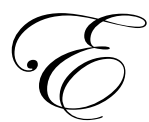

veryone is often under pressure to get things done on time and to meet the deadline, but most of us complain that "there is no time" to finish the required job. This complaint raises a number of questions: 1) Why is time given as an excuse for not finishing a job? 2) Why is there never enough time to do the work? 3) Is the workload greater than the working hours or are working hours wasted? and 4) Does time really fly or is it mismanagement of the available time?

Tutors' ability to manage time is very important in handling such workload and to produce good quality work in a given time. In their study of perceived stress among regular classroom teachers, Hawkins and Klas found that time management was the highest ranking stressor (Shelly, 2004). Time management is often associated with tasks to be carried out or a job to be done, but the real value of time management is the way people can use their available time to make their life easy and carry out their duties. In our day-to-day life, we often use time as an excuse for not finishing a job or completing an assignment. It is true that everyone is under pressure to get things done in a given period of time, but there are never not enough hours in the day, as we always argue.

If a tutor does not finish his/her work, he/she takes it home. This situation gives rise to tension, stress, continuous questioning of the subordinates by senior staff, and - if not seriously discussed - may lead to the breakdown of the individuals at all levels. As Tracy (2001) mentioned, when teachers take their work home, they are trading hard time for soft time and neglecting the time they should be spending with their families.

Managing time is a common issue to many people. An ex-military woman, who stayed at home and started a family, wrote: "I feel like go-go-go, do-do-do all day long and still just barely scrape by not doing anything well. I have scheduled time to do my school work every evening, but what about all the other stuff - the stuff I would consider most important and my main priority?" (http://community.elearners.com/blogs/liberty_university). She listed a number of activities, such as taking care of her two young kids, feeding and watering her pets and birds, meal preparation, and basic household cleaning, as most important.

For tutors, time is even more important. According to Shelly (2004), when teachers have more time for planning and collaborating, they can be more creative; and when they feel overwhelmed and starved for time, there will be no creativity and only the basics of the curriculum will be targeted. 
Tutors at the AOU have a lot of things to do, such as:

1. planning lessons and preparing materials they will use in their teaching

2. preparing exercises and exams for students

3. marking exercises and exams that students have done

4. attending faculty meetings

5. working on research and non-teaching activities

6. participating in professional development programs

Given such workloads, how can tutors find time to do their jobs? In borrowing Ailamahi and Gehrke's (2003) answer, "with good time management", it could be argued that good time management skills and strategies are essential in order to find time for things we have to get done. Norris also brings our attention to the need to "balance the expenditure of our time based on the priorities that we set based on our personal governing values". However, managing time is something that very few tutors or faculty members are prepared for (McClain, 2003), so the need is not to emphasize the importance of time management techniques, but where to have time to learn and develop them.

The first experience of a tutor of a second level Social Sciences course at UKOU was described by the tutor as, ".... I asked pairs of students to introduce themselves to each other and then to introduce their partner to the whole group... It seemed a good ice breaker and I think it brought out a lot of useful information about students' experiences and concerns. Hence, it took longer than I expected." The same tutor wrote about unintended consequences of social intervention, “... I asked groups of four to look at a card and, thinking of illustrations from the course units, to try and explain their phrase in two or three sentences. We had to rush as time was running out. It took about 15 minutes, but could have gone on longer."

What this tutor was complaining about appears to be either the continuous shortage in time or the mismanagement of available time from the side of the tutors. Complaints like "it took longer than I expected", "time was running out", and "we ran out of time as usual" are frequently heard from the tutors. However, one can decide on this issue if he reviews the list of "tutorial techniques and activities" described in the UKOU Teaching Toolkit (p.10), which includes brainstorming, snowballing, discussion, debates, syndicate groups, buzz groups, role play, simulation, games, and hot seat, among other techniques to be used by the tutor and activities for students' involvement.

In general, many people do not know how to manage their time effectively, or they do not believe in planning. Good management is always determined by the capability of individuals to manage available time effectively. University students may become overwhelmed with a feeling that there is not enough time to complete their assignments on and off campus. However, they are often trapped by poor time management behavior, such as last-minute cramming for examinations, which leads to stress and poor academic performance (Alay and Kocak, 2002, 10).

For AOU tutors, managing time has become a more crucial and critical issue due to the nature of the open learning and unique teaching strategies used. The AOU uses a combination of high quality learning materials and face-to-face teaching where instructors encourage students' contribution and self learning. Every assignment done by students must receive detailed feedback and commentary by the tutor for the purpose of facilitating students' learning.

Time constraints severely affect performance, and it could be argued that there is always enough time, but people do not know how to - or intentionally do not want to - manage it. So, are tutors and staff tutors (program coordinators) at the AOU ready to identify the course(s) of this situation? How do they plan for their activities? It is the aim of this paper to answer such questions and clarify them. 


\section{OBJECTIVES}

This paper intends to:

1. investigates the obstacles and problems preventing tutors and staff tutors (program coordinators) at the AOU from effectively managing their time

2. bring the AOU tutors' attention to the importance of managing the available time

3. provide recommendations to the AOU tutors and program coordinators on how they may organize and prioritize daily tasks, manage workflow, and develop a daily plan

4. $\quad$ suggest tips on how to handle interruptions

\section{RESEARCH QUESTIONS}

Lack of time is one of the reasons given by the tutors and program coordinators at the AOU for not developing subject areas and/or their career. It is the aim of this paper to clarify what is behind these complaints, as well as attempt to answer the following questions:

1. What are the duties and responsibilities of tutors and staff tutors at the AOU?

2. What are the obstacles and problems preventing tutors and staff tutors at the AOU from effectively managing their time?

3. What time management strategies can be used for effective time management?

\section{METHODOLOGY}

In the light of methods used in - and the findings of previous research on - time management, as well as considering the type of data needed, and given the purpose of this research paper, face-to-face group interviews were chosen as the most suitable data collection tool. The researchers collected data from the tutors and staff tutors at Kuwait Branch regarding their views on managing time. The interview questions were grouped and categorized according to the research questions under the following headings:

\footnotetext{
- $\quad$ planning time

- workload

- constraints
}

In order to avoid selection of a biased sample, 15 out of 20 tutors were selected as research participants (respondents). The excluded five tutors participated in the pilot study. They were useful as tryouts, helpful in discussing the interview procedures, and in identifying possible sources of bias and/or any threatening questions.

To ensure commitment and cooperation from the respondents, a meeting with the interviewers (researchers) was held prior to the interviews. The researchers clearly explained the purpose of the study and the nature of the interviews to be conducted. Recognizing the importance of their participation, and due to their busy timetable, they kindly agreed to schedule the interviews during weekends.

The participants were divided into three groups of five participants in each group. In the presence of both interviewers, a three-hour long interview was conducted with each group. All interviews were conducted and completed as planned. The use of focused group interviews allowed for collection of in-depth information through face-to-face verbal interactions between group members and the interviewers.

\section{The AOU Teaching Staff}

Staff tutors (program coordinators) are assigned by the Dean of the Academic Program (DAP) in collaboration with the Branch Director (BD) to be located at the Branch and work as the Head of the Academic Department (HAD). She/he is responsible to both the DAP and the BD and performs the following tasks: 
1. makes recommendations to the BD on the appointment of new tutors (lecturers)

2. supervises and makes recommendations to the $\mathrm{BD}$ on the completion of probation by new tutors (lecturers)

3. inducts, trains and supports tutors (lecturers) to ensure the effective tuition of the courses

4. monitors/assists course teams (coordinators) in following the quality assurance measures

5. visits tutors (lecturers) during tutorials to ensure effective tuition and provides constructive feedback

6. reports to the Academic Skills Development \& Training Unit (through the concerned deanship) about the training needs for tutors, in general, and the new recruit, in particular

7. reports on the course(s) and staff performance

8. contributes to teaching

Tutors (lecturers) are expected to perform the following tasks:

1. provide tuition face-to-face and at a distance

2. help students become reflective learners

3. monitor students' progress

4. evaluate individual students' needs for additional support

5. help new students develop learning skills

6. offer general guidance on choosing courses

7. help students to prepare for face-to-face tutorials

8. help students prepare for examinations (AOU Staff Tutors/Tutors Guide: 2002, 15)

To perform these tasks and other related ones, tutors at the AOU have to acquire enough information about distant education, in general, and open learning, in particular, with all their modes of learning, modular instructional material, rules and regulations, enrolment, registration, temporary withdrawal, and examination and grading systems. The responsibilities of tutors at open learning universities are intense and more complicated than those of their colleagues at conventional universities. For example, the teaching responsibility, in the case of open learning, is a two-fold process - the tutor conducts face-to-face contact inside the classroom during weekly sessions. These sessions are important in the "blended" type of learning adopted at the AOU. They are well-planned to match the students' interest and the professional tasks of meeting with students and discussing prescribed subjects in the specific courses assigned to them (AOU Staff Tutors/Tutors Guide:2002,21). In addition, tutors hold a tremendous role of following up the learning process through continuous contact with their students. This process includes contacts during office hours, e-mail, especially designed group chatting through the Learning Management System (LMS), and phone calls.

Helping students to become "reflective learners", as stated to be the second task above, includes a wide range of activities that require daily contact between the tutor and her/his students. Students often seek tutors' advice in matters related to registration, fees, timetable, and academic and administrative implications of not attending classes, not registering during the specified time, and withdrawal from a course.

Given such workloads, tutors struggle with effectively managing time and fixing their schedules to perform these responsibilities and to find time for other social responsibilities, as well as personal endeavors. It is not easy to strike a balance between all of these duties and activities, especially in the Arab community where social values are of no less importance than work tasks.

\section{The AOU Students}

The AOU currently enrolls 29,000 students in its seven regional branches (Kuwait, Saudi Arabia, Jordon, Lebanon, Bahrain, Egypt and Oman). It is expected that by 2020, one out of five persons in the Arab world will know someone who is a student or graduate of the AOU. However, according to the laws and regulations laid by the local educational authorities in the region, the AOU is not allowed to admit students who failed their secondary school certificate. Furthermore, enrolment is decided according to available seats, thus leaving hundreds of thousands of eligible candidates outside higher education institutions. 
Compared with the United Kingdom Open University (UKOU), over 113,000 students register annually at the UKOU. Those students are of all ages and they range from those who left school without qualifications to others who attended "some sort" of higher education. This means that the range of diversity of the AOU students is greater than that of traditional universities. The following aspects are noted:

Age

Traditional universities enroll high school graduates who are 18 years old, whereas the age of students at AOU ranges from 18 to 40 years.

Working Students

While students at traditional universities are young, mostly not working, and considered as full-time students, the AOU students are working on a full or part-time basis and are considered part-time students.

\section{Social Status}

Students at traditional universities are young and mostly unmarried, while a considerable number of students at the AOU are married and are raising families.

\section{Academic Experience}

Traditional university students are new to higher education, but a considerable percentage of the AOU students have gone through some sort of higher education.

\section{Ethnic, Religious and Political Factors}

About half of the students in some branches of the AOU (Kuwait, Bahrain, and Saudi Arabia) are not citizens of those countries. They are expatriates from different nationalities (mainly Arabs) working in these oil-rich countries. As they are not allowed to enter state universities and private ones are very expensive and require full-day attendance, they prefer the flexible, less expensive - and yet excellent - type of open learning at the AOU.

\section{Economic Background}

The AOU is a non-profit organization found to provide higher education for those who, for different reasons, are not able to get it, especially women and those who could not afford the high cost.

\section{The AOU Teaching Strategy}

As a teaching strategy, the AOU uses a combination of high-quality learning materials and face-to-face teaching by tutors who strongly encourage students' contribution and self learning. Tutors support students through written instructions and guidance in response to their written work (TMAs). Every assignment must receive detailed feedback and commentary by the tutor for the purpose of facilitating students' learning (tutors in open learning are facilitators rather than instructors). Students are also supported through individual contacts (office hours), and electronic communication (Learning Management System - LMS, e-mail, group chatting, video conferencing). The actual time that tutors in the AOU need could be determined on the basis of the following factors:

1. the assigned responsibilities, which are stated in the contract and in accordance with the university regulations and bylaws

2. extra responsibilities (academic or non-academic) that are assigned by the university's management

3. $\quad$ career development activities, such as research conferences

4. personal activities, such as family commitments and social relations

5. psychological situations, such as no desire to work, tension, and depression 
In addition, direct face-to-face tutorial sessions are conducted by the tutors and are considered one of the most important teaching methods in distance learning. In these sessions, which are well-planned to be relevant to the students' interests and professional tasks, tutors meet students to discuss prescribed subjects in the specific course assigned to them (AOU Staff Tutors/Tutors Guide: 2002, 21).

Comparing their situation at the AOU with their counterpart in traditional universities, tutors were complaining about unending workloads they have to conduct. Unlike the conventional type of university teaching they are used to - and prepared for, the open learning system requires much more work, such as planning and managing tutorial sessions, encouraging students to self-learn, constructing quizzes and exams, group marking, marking assignments and writing comments for each student, academic counseling for students, and participating in community service and professional development programs. With such workloads, the role of the tutor at the AOU has become more complicated than her/his colleague at the traditional university, as well as the UKOU. The differences can be summarized as follows:

1. At the UKOU, most of the courses are given online and students are not required to attend the classes. In this concern, the AOU follows a "blended" type of instruction in which students are required to attend 75\% of the total teaching hours. This face-to-face contact requires more effort from the tutor.

2. Tutors at the UKOU are "facilitators" rather than instructors. At the AOU, students' expectations from the tutors are very high. They expect tutors to explain, discuss, and sum up each chapter of the textbook. It will take a long time before students at the AOU become familiar with open learning and stick to its rules due to the fact that AOU students still consider their tutors as instructors rather than facilitators.

3. At the UKOU, exams are marked by specialists hired at the end of each semester, while the tutors at the AOU do the whole job - teach, invigilate exams, and mark the answer sheets anonymously.

4. Tutors at the AOU actually work 40 hours per day. They are required to be in their offices from 08:00am to $15: 00 \mathrm{pm}$, five days a week and attend classes on the sixth day. In addition, they are to teach evening classes and attend office hours.

5. Tutors at the AOU are involved, as members or chairpersons, in many committees and are required to do some administrative assignments.

\section{RESULTS AND DISCUSSION}

The respondents indicated that they usually do not finish their work during the workday; therefore, they take their work home in order to get it done on time. In fact, they sometimes work on the weekends to complete it. This situation explains why most of the AOU tutors do not have time to join career development activities.

With regard to planning time, the research participants emphasized do their work in order of priority - they prepare a daily-to-do list and plan their day before it starts. Planning and prioritizing the required tasks means no last-minute rush to get the job done. This explains why the majority of the tutors claimed that they get their job done on time and with no rush. As part of their plans, the respondents said they set deadlines for completing their work.

Respondents argued that they do not lack good time management skills. As they mentioned earlier, they finish work on time, even if they have to take it home. However, they always feel that they are under time pressure to get their job done.

Due to excess of the teaching load and busy schedule, the respondents agreed that it is difficult for them to participate in other faculty activities. One of the tutors said, "The pressure of work has increased as the load is increased, and to make it worse and more difficult, we are required to put our comments on the Learning Management System (LMS). That means downloading, marking on soft copy, ballooning and then uploading it again! This is being implemented to ensure that tutors are under pressure and over worked, without realizing that this has really de-motivated and demoralized us".

No complaints have been recorded regarding interruption by visits of colleagues or phone calls. However, the respondents complained from unexpected assignments thrown at them by their seniors and from unplanned meetings called for by the University management. Such unplanned activities and unexpected assignments make it difficult for them to stick to their plan and result in delay of work. 
Respondents believe that the use of the Learning Management System (LMS) increases the burden of the work rather than ease and enrich their communication with students. In addition, they consider students' counseling as time-consuming due to the relatively large number of students assigned for each tutor. This explains why some tutors think that they are intentionally being put under pressure.

The AOU tutors consider lack of time, or limited time, as the main reason for not finishing their job on time. On the other hand, tutors did not ask for more time, but for a healthy work environment where they can make better use of their available time and thus become more productive. From the tutors' point of view, the work environment at the AOU is characterized by providing no privacy, being too noisy, and consisting of crowded offices where a large number of tutors share a small office.

Therefore, the researchers argue that the solution is not allowing "more time" or "less workload", but a better work environment that allows the tutors to manage their own time. It seems that managing time is a common problem rather than an individual one, so it cannot be solved separately on an individual basis. A tutor said that he made plans and attempts to organize and manage his time, but his plans were ruined by other colleagues and the existing work environment. This means that collective action and efforts at the university level need to be taken to help tutors manage their time.

The respondents also indicated that they are not asking for more time to be able to do their job. They claimed that the prevailing environment of continuous pressure from the side of the university management does not help them to finish their job on time. This pressure takes different forms, such as:

1. high teaching load, particularly if considering the requirements of continuous assessment of students

2. the responsibility of counseling a large group of students (about 40 to 60 ) from admission to graduation

3. The use of the LMS increases the burden and complicates the learning process. As argued by the tutors, it takes a lot of the tutors' time to view each student's work, read, mark, and write comments.

The LMS provides a virtual learning environment in which students and their tutors can communicate via forum, calendar, electronic messages, chatting, and daily contacts. The virtual learning environment provides information about all courses, names of students registered in each course/section, and enables the student to vote electronically, submit her/his assignments, and receive tutors' comments. The tutor is also able to mark students' work, send grades to them, receive feedback, and follow up on students' achievements.

The researchers consider it essential for the tutors to utilize the LMS. It is not time consuming; it helps students toward effective learning provided both tutors and students are well-trained to utilize and use it. Regarding the situation at the AOU, most of the students and some tutors are resisting the use of the LMS because they are not familiar with it and are not well trained. In addition, the number of students taught and supervised by each tutor is relatively high (minimum of 160 per semester).

\section{RECOMMENDATIONS}

First, in the view of the study outcomes, tutors shall categorize their work according to priorities into the following types:

1. work that needs to be finished within a given time

2. work that needs to be done, but no deadline is given

3. work that can be delegated or cancelled

Most of the work assigned to AOU tutors falls into the first category. They have to do a lot of preparation and planning before conducting sessions. They stick to a detailed course calendar showing which lesson/unit/part of the material is to be covered, in which week of the month, and at what time, throughout all University Branches in seven countries. The course calendar also fixes dates for quizzes, mid-term tests, final exams, and cut-off-dates for submitting TMAs throughout all of the AOU branches. 
Second, tutors and students shall intensively use the LMAs, the internet and other means of virtual communications. Therefore, training programs in means and methods of communication need to be organized.

Third, the university administration shall pay more attention to the betterment of the work environment. There should be a plan to provide office space with office equipment for each tutor.

\section{AUTHOR INFORMATION}

Dr. Omer H. Ismail is Assistant professor of Educational Administration at the Department of Foundations and Educational Administration, Faculty of Education, Sultan Qaboos University, Muscat, Sultanate of Oman. He got his Maters and Ph.D. degrees from Pennsylvania State University, USA. He also taught at universities in Sudan, Saudi Arabia, United Arab Emirates and Arab Open University, Kuwait.

Dr. Abdin M. Sharif is Associate Professor of Education and Associate Dean at the Faculty of Education, Arab Open University, Kuwait. He got his Ph.D. from University of Reading, UK, and Masters from Indiana University, USA. He also taught at University of Bahrain, Bahrain and at King Saud University, Saudi Arabia.

\section{REFERENCES}

1. Ailamahi, A. and Gehrke, J. (June, 2003). Time Management for New Faculty. SIGMOD Record, 32(2):102-106.

2. Arab Open University (2002). Staff Tutors/Tutors Guide.

3. Bell, D. and Ritchie R. (1999). Towards Effective Subject Leadership in the Primary School, Open University Press, Buckingham, Philadelphia.

4. McClain, L. (Dec 16, 2003). Lesson on Time Management. http://chronicle.com/article

5. $\quad$ Norris, T. Time management: A key Faculty Survival Skill. http://depts.washington.edu/facdev/newsletter/timemgmt.html

6. Open University (1992). Effective Tutorials.

7. Open University (2000). Supporting Open Learning.

8. Open University (2001). Teaching with the Open University and Course Information.

9. Shelly, P. (Sep 22, 2004). Research on Improving Teacher Time Management. Academic Exchange Quarterly.

10. Time management. http://community.elearners.com/blogs/liberty_university. Retrieved on Dec 15, 2009.

11. Tracy, B. (2001). Managing Your Time. Time Management Tools, Retrieved http://www.timemanagement-tools .com/articles/managing-your-time.htm. 